\title{
Developmental Patterns of Mucin Gene Expression in Human Fetal Small Intestinal Xenografts Maintained in Severe-Combined Immunodeficient Mice
}

\author{
MARIE-PIERRE BUISINE, JEAN-PIERRE AUBERT, W. ALLAN WALKER, AND TOR C. SAVIDGE \\ Unite 560 INSERM and Laboratoire de Biochimie et de Biologie Moleculaire, Hopital C Huriez, Lille, \\ France [M.-P.B., J.-P.A.]; Laboratory of Developmental Gastroenterology, Combined Department of \\ Pediatric Gastroenterology and Nutrition, Massachusetts General Hospital and Harvard Medical School, \\ Charlestown, Massachusetts, U.S.A. [W.A.W., T.C.S.]
}

\begin{abstract}
ABS
The lack of a suitable animal model that expresses human
intestinal mucin genes limits the study of mucin function. The
aim of this study was to examine whether human fetal intestinal
xenografts, known to model host-restricted interactions with
human-specific pathogens, express mucin genes in an appropriate
developmental pattern when transplanted into severe-combined
immunodeficient (scid) mice. Expression profiles for eight mucin
genes were examined in human fetal ileal xenografts transplanted
ectopically into scid mice for 10 wk. In situ hybridization was
performed on fetal, xenograft, and adult intestinal tissue sections
with ${ }^{35}$ S-labeled oligonucleotides specific to human tandem re-
peat sequences for $M U C 1, M U C 2, M U C 3, M U C 4, M U C 5 A C$,
$M U C 5 B, M U C 6$, and $M U C 7$. Hybridization patterns observed
with the $M U C 2, M U C 3, M U C 4$, and $M U C 5 A C$ probes demon-
strated that mucin gene expression in xenografted fetal intestine
was comparable to third trimester fetal and/or adult tissues.
\end{abstract}
In the gastrointestinal tract, mucus forms an abundant and continuous layer that lines the apical surface of intestinal epithelial cells. This mucus is predominantly produced and secreted by epithelial goblet cells, and serves several protective and lubricative functions during digestion and peristalsis. Being permeable only to low molecular weight molecules such as nutrients, mucus also limits the exposure of the intestinal mucosa to potential parasitic, bacterial, and viral pathogens in the gut lumen. These physical properties of mucus can be largely attributed to its mucin composition $(1,2)$. These high molecular weight and heavily

Received November 1, 2001; accepted October 10, 2002.

Correspondence: Dr. Tor Savidge, Developmental Gastroenterology Laboratory, Combined Program in Pediatric Gastroenterology and Nutrition, Massachusetts General Hospital and Harvard Medical School, 114 16th Street, Charlestown, MA 02129, U.S.A.; e-mail savidge@helix.mgh.harvard.edu

Supported in part by National Institutes of Health grants RO1-HD31852, PO1DK33506, P30-DK40561, and R37-HD12437.

DOI: 10.1203/01.PDR.0000064582.30004.62
MUC2 and MUC5AC were expressed in a developmentalspecific fashion. $M U C 5 A C$, expressed in first and early second trimester fetal bowel, was never detected in intestinal xenografts. $M U C 2$ expression displayed a late fetal and/or adult-type hybridization pattern. MUC3 and MUC4 were not developmentally expressed. Appropriate developmental regulation of known intestinal mucin genes was recorded in ectopically grafted human fetal intestinal xenografts. Adult-like patterns of mucin gene expression in this model system will permit future studies aimed at characterizing cis/trans-acting factors that regulate mucin gene expression and function during development, disease, and wound healing and also in mucin-pathogen interactions during host defense. (Pediatr Res 53: 898-904, 2003)

\section{Abbreviations \\ scid, severe-combined immunodeficient}

glycosylated O-linked glycoproteins impart a profound viscoelasticity and density to mucus, although the exact functions of specific mucins remain to be determined.

To date, eight different mucin genes (MUC1, MUC2, MUC3, MUC4, MUC5AC, MUC5B, MUC6, and MUC7) have been identified and well characterized $(3,4)$. All mucin genes share common features, including tandemly repeated sequences flanked by nonrepeat regions. Tandem repeat units vary in length from eight amino acid residues in $M U C 5 A C$ to 169 amino acid residues in MUC6. Several mouse (Muc1-4, Muc5ac, Muc5b, and Muc7) and rat (rMuc1-4, rMuc5ac, and rMuc7) homologues to human mucin genes have also been cloned. Interestingly, although they show a high sequence similarity with their human homologues in their nonrepetitive and promoter regions, tandem repeats differ significantly in sequence and size $(3,5,6)$.

Expression of human mucin genes has been shown to be tissue and cell specific. Individual or a co-ordinated expression 
of individual members of the mucin gene family are associated or contribute directly to cellular function [e.g. MUC1 and MUC4 promote and inhibit cell adhesion, respectively (7-9)], tumorigenesis [e.g. aberrant expression of MUC5AC in colorectal adenomas $(10,11)]$, and embryogenesis. In the latter example, distinct developmental mucin gene expression profiles are observed for human fetal lung, stomach and intestine that may contribute to tissue specific ontogenesis (12-16). In the developing respiratory tract, $M U C 5 A C, M U C 5 B$, and $M U C 7$ are strongly expressed with $M U C 1, M U C 2$, and $M U C 4$ during periods of glandular and alveolar epithelial cytodifferentiation (13-27 wk of gestation) (15). Similarly, MUC5AC and MUC6 are strongly expressed with $M U C 1$ and MUC4 in embryonic and fetal stomach (8-27 wk of gestation) (16).

In contrast to mucin gene expression in the human fetal respiratory tract and stomach, intestinal ontogenesis is predominantly associated with the expression of $M U C 2, M U C 3$, $M U C 4$, and $M U C 5 A C$ genes. These genes, except for $M U C 3$, are all differentially expressed in fetal as compared with normal adult gut (12-14). The extent of this differential expression is directly dependent on the stage of development inasmuch as normal adult mucin gene expression profiles are apparent in fetal intestine at 26-27 wk of gestation. For example, MUC2 gene expression in adult bowel is primarily restricted to the perinuclear region of villus and crypt goblet cells. However, up to $23 \mathrm{wk}$ of gestation, fetal MUC2 expression is located predominantly within the immature crypts of Lieberkühn, with little or no expression in villus goblet cells (12-14). In adult bowel, moderate MUC4 expression is only consistently found in colonic epithelial cells, whereas a homogeneous signal is detected throughout the fetal small and large bowel up to approximately $15 \mathrm{wk}$ of gestation $(13,14)$. MUC5AC is moderately expressed in fetal intestine up to 12 wk of gestation, whereas it is never detected in adult bowel unless this shows early stages of neoplasia $(10,14,17)$.

The study of mucin gene expression is complicated not only by the fact that many of these genes are human specific, but they are also expressed in a tissue- and developmental-specific fashion. The present work describes the developmental expression of eight mucin genes in human fetal small intestine xenotransplanted subcutaneously into scid mice. This approach has previously been used to study human-specific developmental regulation of epithelial proliferation and cytodifferentiation (18-21). These studies demonstrated that ectopic grafting of different regions of human fetal intestine for $10 \mathrm{wk}$ or longer promoted appropriate tissue development in the absence of conventional lumenal and/or systemic stimuli that are normally present in utero. Epithelial goblet cells differentiate normally in this model and are especially abundant in ileal and colonicderived xenografts, where they produce large quantities of mucus $(20,21)$. It is not know at this stage, however, whether mucin gene expression is appropriately regulated in the absence of luminal stimuli present in amniotic fluid, as well as from gastrointestinal, pancreatic, and bile secretions.

Using in situ hybridization, we demonstrated that the pattern of mucin gene expression in early second trimester fetal ileum develops appropriately when transplanted as xenografts into scid mice for $10 \mathrm{wk}$. At this stage, mucin gene expression correlated well with that observed in human fetuses of 23-26 wk of gestation to an adult hybridization pattern and as such reaffirms the suitability of this model system to study human gastrointestinal developmental regulation. In addition, these findings now allow in vivo studies designed to examine the role of human mucins in wound healing and in host-pathogen interactions, as well as testing the biologic effects that antimicrobial and probiotic agents have in inhibiting the binding of pathogens to intestinal mucins and thereby preventing their attachment to human intestinal epithelial cells.

\section{METHODS}

Materials. Materials were obtained from Sigma Chemical (St. Louis, MO, U.S.A.) unless otherwise stated.

Xenotransplantation of human fetal small intestine. Human fetal ileum was obtained from the MRC Tissue Bank (Royal Marsden Hospital, London, UK) (15 samples; mean, $14.2 \pm 1.6 \mathrm{wk}$; range, $10.2-16.3 \mathrm{wk}$, as assessed by crownrump length), after therapeutic abortion. Procurement and procedures involving xenografting of human fetal tissues into C.B-17 scid/scid were performed with full approval from the local ethics committees and in accordance with the Home Office guidelines specified in the Polkinghorne Report (22). Before transplantation, fetal tissues were washed twice in ice-cold serum-free Dulbecco's Modified Eagle's Medium and xenotransplanted into scid mice as described previously (20). Briefly, intact segments of fetal intestine $(2-3 \mathrm{~cm}$ lengths) were transplanted subcutaneously onto the back of 6- to 8-wk-old female and male mice maintained in negative pressure isolators supplied with HEPA filters. Mice had access to sterilized food (Labsure, K\&K Greef Ltd., Croyden, UK) and water ad libitum. Intestinal xenografts were harvested after $10 \mathrm{wk}$ and were compared with results obtained from pretransplanted fetal and histologically normal fetal, pediatric, or adult biopsy samples obtained from routine investigative procedures with fully informed consent and local ethical committee approval. Additional samples were obtained from fetuses after spontaneous (10.5 wk of gestation, male, without malformation) or therapeutic abortion (12 wk of gestation, male, maternal pathology; 23 wk of gestation, male, trisomy 21; 26 wk of gestation, male, hydrencephaly (lissencephaly of Walker-Warburg type). This material was used in a previous study (14) and served in the present study as control. As adult controls, ileal biopsy specimens were taken from four patients (three females, one male; mean age, $35 \mathrm{y}$, range, $18-50 \mathrm{y}$ ) who underwent endoscopy for irritable bowel disease. No endoscopic lesions were found in these patients.

For routine morphologic analysis and in situ hybridization, tissues were fixed in $10 \%$ phosphate-buffered formal saline $(\mathrm{pH} 7.2)$ for $24 \mathrm{~h}$ and embedded in paraffin using routine procedures. Sections ( $3 \mu \mathrm{m}$ thick) were stained with hematoxylin and eosin (H\&E) or periodic acid Schiff's (PAS) stain, or were processed for in situ hybridization. For ultrastructural studies of goblet cells in xenograft intestine, tissues were fixed in $4 \%$ phosphate-buffered $(\mathrm{pH}$ 7.2) glutaraldehyde and processed for electron microscopy using conventional methods. 
In situ hybridization. In situ hybridization was performed using eight ${ }^{35} \mathrm{~S}$-labeled human-specific oligonucleotide probes corresponding to each tandem repeat domain of $M U C 1$, MUC2, MUC3, MUC4, MUC5AC, MUC5B, MUC6, and MUC7. Oligonucleotide sequences and details of the hybridization steps have been described previously $(15,23)$. Briefly, sections of small intestine were deparaffinized, rehydrated, and treated with proteinase K $(2 \mu \mathrm{g} / \mathrm{mL}$; Roche Molecular Biochemicals, Meylan, France) for 15 min at room temperature. Sections were then fixed with phosphate-buffered $4 \%$ paraformaldehyde ( $\mathrm{pH}$ 7.2) for $15 \mathrm{~min}$ before incubating for $10 \mathrm{~min}$ with $0.1 \mathrm{M}$ triethanolamine containing $0.25 \%$ acetic anhydride. Sections were prehybridized for $45 \mathrm{~min}$ in $4 \times$ SSPE (standard sodium phosphate EDTA) and $1 \times$ Denhardt's buffer, and hybridized overnight at $42^{\circ} \mathrm{C}$ in $4 \times \mathrm{SSPE}$ containing $50 \%$ formamide (vol/vol), $0.1 \% N$-lauroylsarcosine (wt/v) (Amersham, Les Ulis, France), 1.2 M sodium phosphate (pH 7.2), $1 \times$ Denhardt's buffer, $3 \mathrm{mg} / \mathrm{mL}$ yeast tRNA, $20 \mathrm{mM}$ DTT, and 7.5 $\times 10^{3} \mathrm{dpm} / \mu \mathrm{L}{ }^{35} \mathrm{~S}$-labeled oligonucleotide. After posthybridization washes, slides were developed for autoradiography using LM-1 emulsion (Amersham), developed after 2-3 wk at $4^{\circ} \mathrm{C}$, and counterstained with methyl green pyronin. Xenograft, fetal, pediatric, and adult sections were treated simultaneously to exclude possible variations between specimens. As controls, sections were either pretreated with $50 \mu \mathrm{g} / \mathrm{mL}$ RNAse A (Roche Molecular Biochemicals) or treated with an excess of unlabeled probe.

\section{RESULTS}

We have previously described that human fetal intestine undergoes a rapid and region-specific differentiation when transplanted ectopically into scid mice $(20,21)$. Tissue regeneration after angiogenesis of the xenografts is associated with the formation and expansion of a de novo epithelial barrier derived from epithelial stem cells that survive the initial ischemic tissue insult. This epithelialization process is initially devoid of goblet cells. However, as the xenograft mucosa develops, the commitment of epithelial cytodifferentiation to the goblet cell lineage becomes increasingly abundant (Fig. 1, $A-C)$. Goblet cell differentiation is induced approximately 3-fold as compared with pretransplanted fetal intestine as determined by PAS (Fig. 1, $A, E$ and G) or alcian blue staining (Fig. 1F). Ultrastructural analysis demonstrated goblet cell maturity with large numbers of homogenous mucous granules (Fig. 1D) that are discharged into the xenograft lumen after infection of the xenografts with, for example, Salmonella typhimurium (21).

Mucin gene expression in fetal and adult intestinal tissues differ greatly, and to study the role that human mucins may play in wound healing and in host-pathogen interactions there is a requirement that the intestinal xenografts develop an appropriate pattern of mucin gene expression. We demonstrate here that appropriate developmental patterns in mucin gene expression are indeed recorded after xenotransplantation of human fetal intestine into ectopic sites.

MUC2 gene expression. In pretransplanted fetal intestine, strong hybridization with the $M U C 2$ probe was primarily recorded within the immature crypts of Lieberkühn (Fig. 2, A and $B$ ). Hybridization was also occasionally observed in individual scattered cells within the villous compartment. Ileal xenografts also showed a similar strong hybridization with the $M U C 2$ probe, although the pattern varied from that observed in approximately 18 -wk-old gestational age fetal intestine to adult bowel (Fig. 2, $B$ and $C$ ). In grafts where villi were still developing, $M U C 2$ gene expression was primarily confined to the crypt region (Fig. 2, $D$ and $E$ ). In developed grafts with

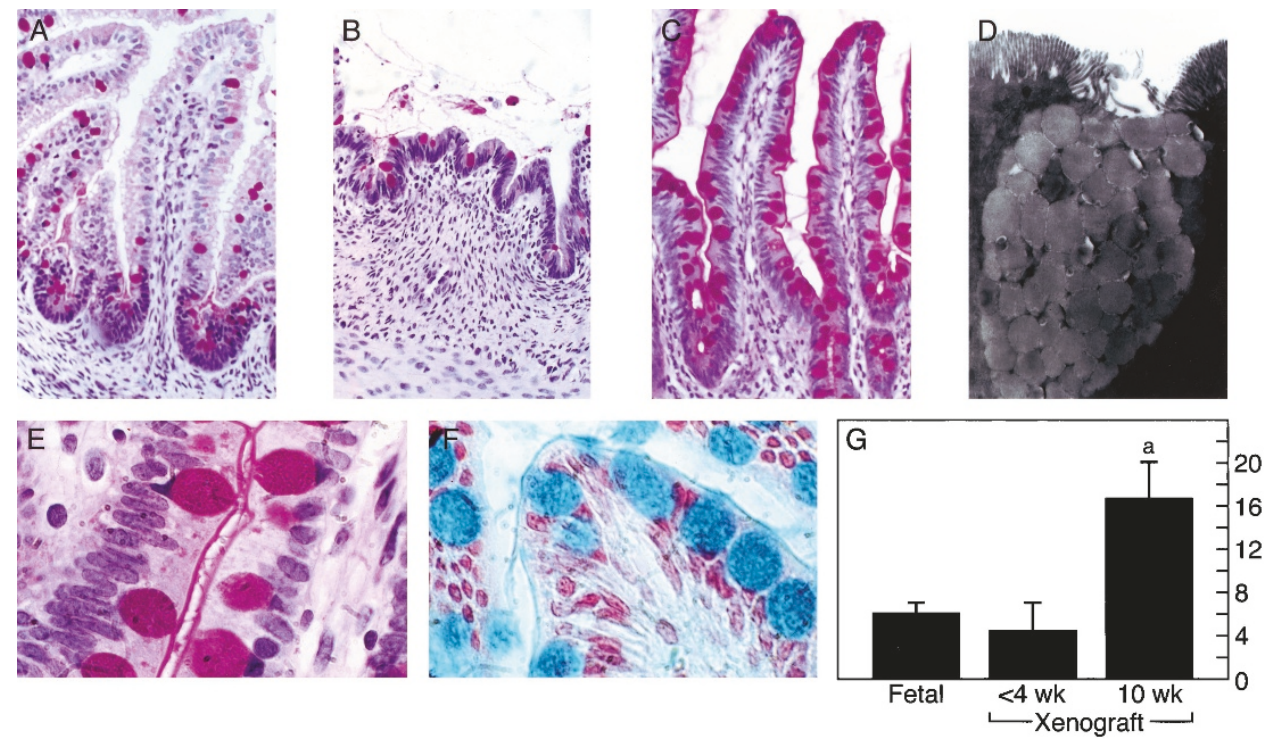

Figure 1. Goblet cell development during xenograft regeneration. $(A-C)$ Goblet cells staining positive with PAS in 12-wk-old fetal, developing xenograft (4 wk after transplantation), and developed xenograft intestine (10 wk after transplantation). Original magnification $\times 200$. $(D-F)$ High-power view of goblet cells stained with PAS $(E)$, alcian blue (magnification $\times 400)(\mathrm{F})$, or processed for transmission electron microscopy (magnification $\times 1228)(\mathrm{D})$ ). $(G)$ Graph showing significant induction of goblet cell $\left(\mathrm{PAS}^{+}\right)$populations during xenograft development before $4 \mathrm{wk}(n=5)$ and at 10 wk $(n=8)$, respectively $[a$, significant difference $(p<0.01)$ between fetal $(n=8)$ or developing xenograft and xenograft bowel after 10 wk; Welsh test; nonpooled for variance]. 

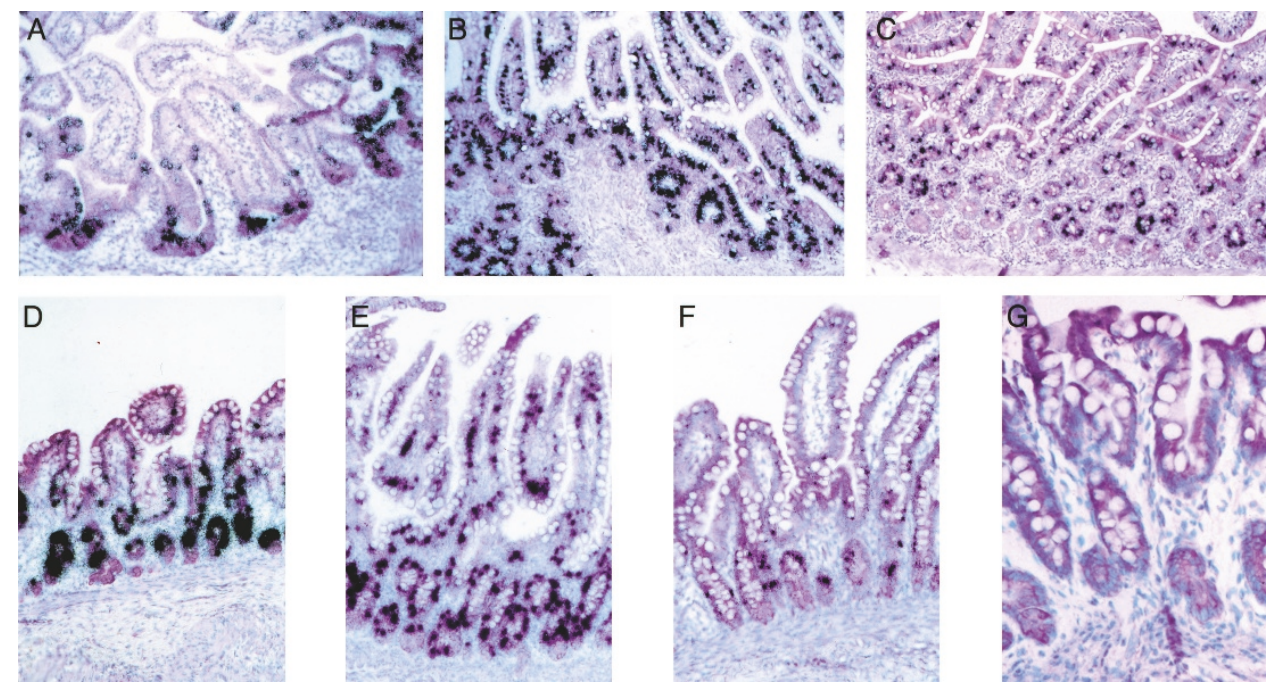

Figure 2. In situ hybridization for $M U C 2$ mRNAs in fetal, xenograft, and adult intestine. (A) Fetal intestine at 12 wk of gestation: the signal is located predominantly within immature crypts of Lieberkühn. Individual scattered goblet cells within the villous compartment are also labeled. Methyl green pyronin counterstain. Original magnification $\times 200$. $(B)$ Fetal ileum at 23 wk of gestation: the signal is stronger in the crypts, but villous goblet cells are also labeled. Methyl green pyronin counterstain. Original magnification $\times 180$. (C) Adult intestine: the signal is located in the perinuclear region of goblet cells both on villi and in crypts. Methyl green pyronin counterstain. Original magnification $\times 100$. $(D)$ Xenograft ileum with shorter villi showing a fetal hybridization pattern similar to $A$ : the labeling is largely restricted to the crypts. Methyl green pyronin counterstain. Original magnification $\times 100$. $(E)$ Xenograft ileum showing a late fetal hybridization pattern similar to $B$ (around $23 \mathrm{wk}$ ): the signal is stronger in the crypts, but villous goblet cells are also labeled. Methyl green pyronin counterstain. Original magnification $\times 100$. $(F)$ Xenograft ileum with well-developed villi showing an adult hybridization pattern similar to $C$ : the signal is located in the perinuclear region of goblet cells both on villi and in crypts. Methyl green pyronin counterstain. Original magnification $\times 100$. $(G)$ Xenograft negative control hybridized with excess of $M U C 2$ cold probe. Original magnification $\times 400$.

well-formed villi, $M U C 2$ mRNA demonstrated an adult-like pattern (Fig. 2C) with hybridization confined to goblet cells on villi and in crypts (Fig. $2 F$ ). The fetal type of hybridization pattern was most often observed in samples where villi were shorted and enlarged, with a visibly reduced villus to crypt ratio. Although all samples were derived from fetal ileum, this possibly suggests a more distal intestinal region and consequently a less differentiated intestine due to the cephalocaudal direction of cytodifferentiation that occurs during human gastrointestinal ontogenesis. Of the 15 xenograft intestinal samples analyzed, three demonstrated a fetal hybridization pattern $(<23 \mathrm{wk}$ of gestation), four demonstrated a fetal hybridization pattern similar to that recorded around $23 \mathrm{wk}$ of gestation, and eight a mixed 23-wk to adult hybridization pattern.

MUC3 gene expression. The MUC3 anti-sense probe hybridized less intensely to the xenograft epithelium than the MUC2 probe. As was observed in fetal, pediatric, and adult bowel, hybridization with the $M U C 3$ probe was largely absent in the crypt epithelium but homogenous labeling was recorded in the villous compartment in both enterocytes and in goblet cells, as is observed in adult bowel (Fig. 3, $A-C$ ). Hybridization was detected in all 15 xenograft samples examined and the pattern did not change with the developmental stage.

MUC4 gene expression. Hybridization with the MUC4 probe was highly variable in the xenograft specimens, labeling only four of the 15 samples, whereas hybridization was recorded in seven of 11 fetal intestinal samples analyzed (Fig. 3D). In the xenograft specimens, weak labeling was observed in the crypt and villous compartment (Fig. 3, E and F). A similar hybridization pattern was observed in fetal, pediatric, and adult ileum, as reported previously (14).
MUC5AC gene expression. MUC5AC mRNA were not detected in any of the xenograft, pediatric, or adult specimens examined. By contrast, hybridization was observed in younger fetuses aged between 10 and 12 wk of gestation (Fig. 3, $G$ and $H$ ), as reported previously (14).

Developmental-stage-specific mucin gene expression. Comparison of the hybridization patterns observed with the $M U C 2, M U C 3, M U C 4$, and $M U C 5 A C$ probes in xenograft intestine demonstrated that mucin gene expression in xenograft intestine correlated well with that of human fetuses 23 to $26 \mathrm{wk}$ of gestation, because MUC5AC was never detected in xenografts and $M U C 2$ displayed a late fetal or adult-type hybridization pattern. These findings demonstrate that $M U C 2$ and $M U C 5 A C$ are the most appropriate genes to assess whether the mucosa is well differentiated. These findings also demonstrate that there is not an aberrant expression of MUC3 and MUC4 genes in xenograft intestine. However, it is difficult to use these genes as developmental stage-specific markers because the distribution of $M U C 3$ mRNA does not change irrespective of the developmental stage. Although MUC4 mRNA are found more frequently in young fetuses, MUC4 mRNA are occasionally detected in older fetuses and in adult ileum.

MUC1, MUC5B, MUC6, and MUC7 gene expression. The expression of these genes was not observed in either fetal, xenograft, pediatric, or adult intestine. These probes have previously been demonstrated to hybridize to embryonic and fetal stomach ( $M U C 1, M U C 5 B$, and MUC6) (16), and lung (MUC1, MUC5B, and MUC7) (15), thereby indicating that the expression of these transcripts in xenografted human fetal intestine is either absent or too low to be detected by in situ hybridization. 

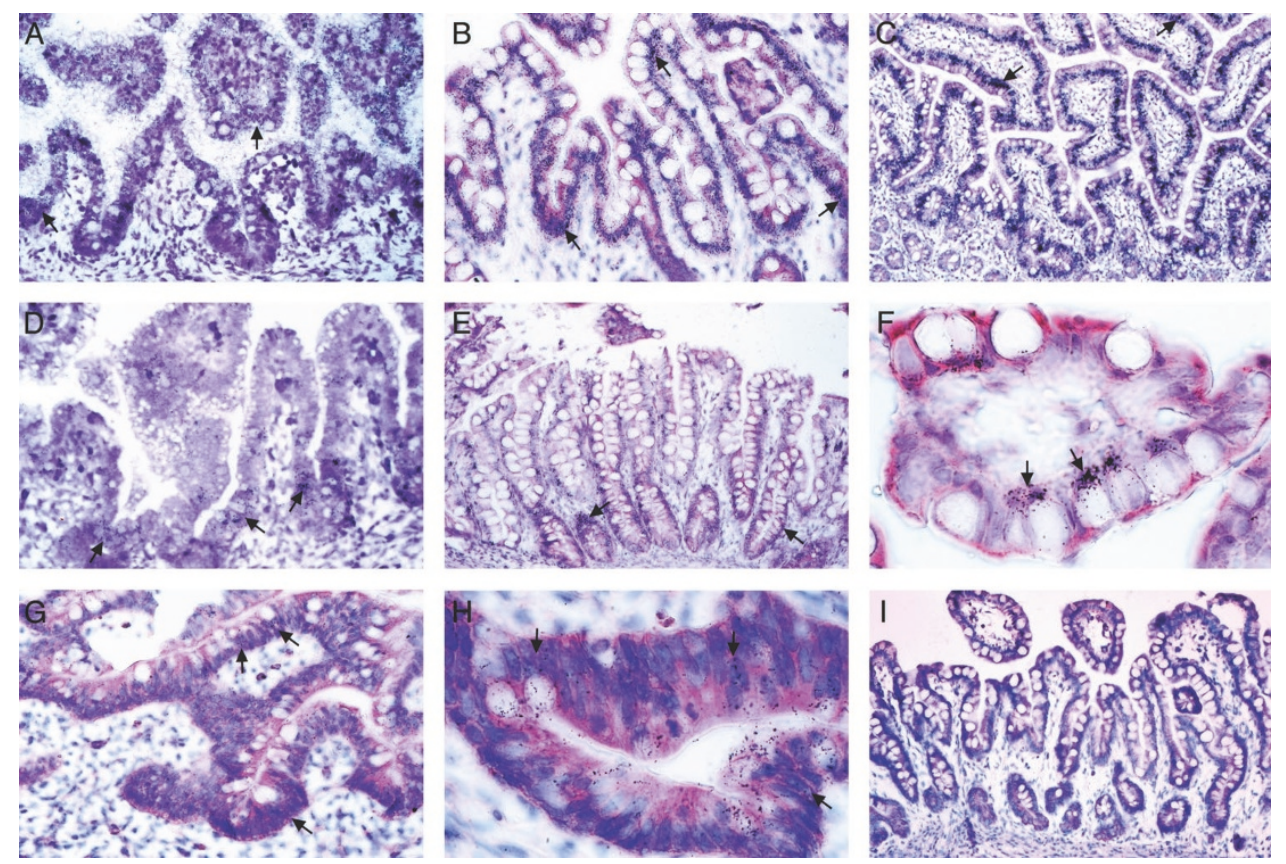

Figure 3. In situ hybridization for $M U C 3, M U C 4$, and $M U C 5 A C$ mRNA in fetal, adult, and xenograft intestine. (A) Fetal intestine at 14 wk of gestation with the MUC3 probe: continuous and homogeneous labeling along the villous epithelium, both in goblet and absorptive cells. No labeling is present in crypts. Methyl green pyronin counterstain. Original magnification $\times 400$. $(B)$ Xenograft ileum with the MUC3 probe: continuous and homogeneous labeling along the villous epithelium, both in goblet and absorptive cells. No labeling is present in crypts. Methyl green pyronin counterstain. Original magnification $\times 400$. $(C)$ Adult intestine with the MUC3 probe: continuous and homogeneous labeling along the villous epithelium, both in goblet and absorptive cells; very weak labeling is also present in crypts. Methyl green pyronin counterstain. Original magnification $\times 100$. $(D)$ Fetal ileum at 14 wk of gestation with the $M U C 4$ probe: scattered cells are labeled both on villi and in crypts. Methyl green pyronin counterstain. Original magnification $\times 200$. $(E, F)$ Xenograft ileum with the $M U C 4$ probe: the signal is located in epithelial cells both on villi and in crypts. Methyl green pyronin counterstain. Original magnification $\times 100 ; 640$. $(G, H)$ Fetal ileum at 12 wk of gestation with the MUC5AC probe: scattered cells are labeled both on villi and in crypts. Methyl green pyronin counterstain. Original magnification $\times 400$, 640. (I) Xenograft-negative control hybridized with excess of $M U C 3$ cold probe. Original magnification $\times 100$.

\section{DISCUSSION}

A number of studies have demonstrated that the composition and spatio-temporal regulation of mucin gene expression in human fetal intestine differs drastically to that in adults. These investigations have unilaterally shown a differential expression of MUC2, MUC4, and MUC5AC genes during the first two trimesters (12-14). One interpretation of these findings has been that this altered gene expression promotes appropriate intestinal ontogenesis. These suggestions are supported, to some extent, by the aberrant expression of MUC5AC and MUC6, and the over-expression of MUC2 mRNA during tumorigenesis $(10,11)$. However, analysis of human gastrointestinal mucin gene expression and its dysregulation in disease states, e.g. neoplasia or chronic inflammation, has to date been restricted to examining patient biopsies that present a static view of events occurring fairly late after the onset of pathology. It is difficult to gain meaningful insights from these types of studies, into possible promoters and trans-acting factors that regulate and/or direct mucin gene expression to appropriate cell lineages within the intestinal mucosa. In addition, use of adenocarcinoma-derived cell lines to study mucin gene expression and function are likely to reflect oncofetal characteristics, and extrapolation of such information back to the adult gastrointestinal tract may be misleading. Hence, we examined the developmental expression profiles for eight mucin genes after ectopic xenotransplantation of human fetal ileum into immu- nodeficient host scid mice for $10 \mathrm{wk}$. Appropriate developmental regulation of mucin genes in this model system will permit future studies aimed at characterizing cis/trans-acting factors and pathways that regulate mucin gene expression and study mucus function in children and adults.

We have demonstrated previously that epithelial cell proliferation and brush border hydrolase activity is regulated in an appropriate developmental fashion in this model system. For example, ectopic grafting of fetal jejunum closely recapitulated the development of these enzymes in utero, with alkaline phosphatase, aminopeptidase-N, $\alpha$-glucosidase, and dipeptidyl peptidase IV enzyme activities closely matching the spatiotemporal distribution and levels recorded in pediatric duodenal biopsies (24). Lactase-phlorizin hydrolase activity was the only enzyme that failed to reach pediatric values, although activities were comparable to late-gestational-age human fetal bowel. The present work demonstrates that $M U C 2, M U C 3$, and $M U C 4$ develop a late fetal or adult pattern of gene expression in human fetal ileal xenografts, and that $M U C 5 A C$, normally expressed in fetal intestine during the first and early second trimester, is appropriately switched off during xenograft development. As described previously for fetal and adult ileum (14, 17) $M U C 5 B, M U C 6$, and $M U C 7$ gene expression was not identified using in situ hybridization, thereby indicating that these genes are appropriately regulated after ectopic grafting of human fetal intestine. 
To our knowledge, this is the first study to recapitulate the developmental profile of human intestinal mucin gene expression using a chimeric experimental animal model system. As the grafts are transplanted into adult host mice, xenograft development occurs in the absence of systemic hormonal influences associated with pregnancy, or luminal signals from amniotic fluid, pancreatic and bile secretions, and the gut microflora. Intestinal mucin gene expression therefore develops appropriately in the absence of these trans-acting signals. Taken together, these results reaffirm the suitability of the xenograft model to study molecular and cellular mechanisms that regulate human intestinal development and maturation.

There is also great potential to use this model system to investigate epithelial renewal in adults under normal conditions, as well as during intestinal wound healing and restitution. Such studies should bring new insights into regulatory factors that are involved in mucosal adaptation to injury and epithelial restitution, including a potential role of the various members of the mucin glycoprotein family. Interestingly, gastrointestinal mucins associated with trefoil factors facilitate restitution of wounded epithelial monolayers (25). Moreover, intestinal mucin glycoproteins act as an important host-defense by binding of pathogenic microorganisms, thus preventing their attachment to epithelial cells and subsequent cytolysis (2). However, mucin glycoproteins can also serve as receptors for a wide range of pathogens that colonize the mucus barrier and epithelial cells. Indeed, numerous enteropathogenic microorganisms, including bacteria (e.g. Shigella sp., Salmonella sp., Yersinia enterocolitica, certain strains of Escherichia coli), viruses (rotaviruses), and parasites (Entamoeba histolytica) have been shown to interact with intestinal mucins (26-31). Intestinal mucins of various species, however, may not contain the same binding sites despite of considerable similarity in their overall chemical composition and physical structures. For example, Shigella binds specifically to human colonic mucin and not to rat colonic mucin (31). Studies with other diarrheacausing organisms, such as $Y$. enterocolitica, have provided similar results with greater binding to human intestinal mucins when compared with various mammalian intestinal mucins (32). Thus, animal models are limited in their usefulness to investigate pathogen-host interactions, as appropriate mucin gene expression may directly contribute to the host-restricted enterocolitis that is evident in human intestinal xenografts that are infected with Salmonella typhi (33-36), Entamoeba histolytica $(37,38)$, Cryptosporidium parvum $(39,40)$, and Helicobacter pylori (41).

Whereas the submucosa and the lamina propria are comprised of a chimeric mixture, the intestinal xenograft epithelium and neighboring intraepithelial lymphocytes, muscularis mucosa, and externa have been shown to be exclusively of a human origin. Several mouse homologues to human mucin genes have been cloned. Although they show a high sequence similarity with their human homologue in their amino- and carboxy-terminal regions, tandem repeats seem to be specific for each specific mucin and show little interspecies conservation $(3,5,6)$. For the in situ hybridization studies, we used oligonucleotide probes corresponding to each tandem repeat domain of the human mucin genes. The positive hybridization signals observed with these specific $M U C$ probes demonstrates the human origin of mucins reconfirming the human origin of the xenograft epithelium. The xenograft model therefore constitutes a suitable model for studying pathogen-mucin interactions and their role in mucosal defense or colonization. Interestingly, more specifically, MUC2 and MUC3 intestinal mucins have been shown to be capable of inhibiting enteropathogen adherence to intestinal epithelial cells in vitro (42). Moreover, probiotic agents (Lactobacillus sp.) increase $M U C 2$ and $M U C 3$ mRNA levels in vitro (42). Thus, determination of the factors responsible for the modulation of mucin expression may be of great therapeutic interest.

\section{REFERENCES}

1. Neutra MR, Forstner JF 1987 Gastrointestinal mucus: synthesis, secretion and function. In: Johnson LR (ed) Physiology of the Gastrointestinal Tract. New York, Raven, pp 975-1009

2. Lichtman SN, Sherman P, Mack DR 1996 The role of mucus in gut protection. Curr Opin Gastroenterol 12:584-590

3. Gendler SJ, Spicer AP 1995 Epithelial mucin genes. Annu Rev Physiol 57:607-634

4. Lagow E, DeSouza MM, Carson DD 1999 Mammalian reproductive tract mucins. Hum Reprod Update 5:280-292

5. Shekels LL, Hunninghake DA, Tisdale AS, Gipson IK, Kieliszewski M, Kozak CA, Ho SB 1998 Cloning and characterization of mouse intestinal MUC3 mucin: 3' sequence contains epidermal-growth-factor-like domains. Biochem J 330:1301-1308

6. van Klinken BJ, Einerhand AW, Duits LA, Makkink MK, Tytgat KM, Renes IB, Verburg M, Buller HA, Dekker J 1999 Gastrointestinal expression and partial cDNA cloning of murine Muc2. Am J Physiol 276:G115-G124

7. Hilkens J, Ligtenberg MJ, Vos HL, Litvinov SV 1992 Cell membrane-associated mucins and their adhesion-modulating property. Trends Biochem Sci 17:359-363

8. Zhang K, Sikut R, Hansson GC 1997 A MUC1 mucin secreted from a colon carcinoma cell line inhibits target cell lysis by natural killer cells. Cell Immunol 176:158-165

9. Komatsu M, Tatum L, Altman NH, Carothers Carraway CA, Carraway KL 2000 Potentiation of metastasis by cell surface sialomucin complex (rat MUC4), a multifunctional anti-adhesive glycoprotein. Int J Cancer 87:480-486

10. Buisine MP, Janin A, Maunoury V, Audié JP, Delescaut MP, Copin MC, Colombel JF, Degand P, Aubert JP, Porchet N 1996 Aberrant expression of a human mucin gene (MUC5AC) in rectosigmoid villous adenoma. Gastroenterology 110:84-91

11. Bartman AE, Sanderson SJ, Ewing SL, Niehans GA, Wiehr CL, Evans MK, Ho SB 1999 Aberrant expression of MUC5AC and MUC6 gastric mucin genes in colorectal polyps. Int J Cancer 80:210-218

12. Chambers JA, Hollingsworth MA, Trezise AEO, Harris A 1997 Developmental expression of mucin genes MUC1 and MUC2. J Cell Sci 107:413-424

13. Reid CJ, Harris A 1998 Developmental expression of mucin genes in the human gastrointestinal system. Gut 42:220-226

14. Buisine MP, Devisme L, Savidge TC, Gespach C, Gosselin B, Porchet N, Aubert JP 1998 Mucin gene expression in human embryonic and fetal intestine. Gut 43:519-524

15. Buisine MP, Devisme L, Copin MC, Durand-Réville M, Gosselin B, Aubert JP, Porchet N 1990 Developmental mucin gene expression in the human respiratory tract. Am J Respir Cell Mol Biol 20:209-218

16. Buisine MP, Devisme L, Maunoury V, Deschodt E, Gosselin B, Copin MC, Aubert JP, Porchet N 2000 Developmental mucin gene expression in the gastroduodenal tract and accessory organs, I. Stomach: a relationship to gastric carcinoma. J Histochem Cytochem 48:1657-1665

17. Bartman AE, Buisine MP, Aubert JP, Niehans GA, Toribara NW, Kim YS, Kelly EJ, Crabtree JE, Ho SB 1998 The MUC6 secretory mucin gene is expressed in a wide variety of epithelial tissues. J Pathol 186:398-405

18. Friedberg JS, Ryan DP, Driscoll SG, Folkman J 1985 Human small bowel transplants into athymic mice and rats. Surg Forum 36:375-378

19. Winter HS, Hendren RB, Fox CH, Russel GJ, Perez-Atayde A, Bhan AK, Folkman J 1991 Human intestine matures as nude mouse xenografts. Gastroenterology 100:89-98

20. Savidge TC, Morey AL, Ferguson DJP, Fleming KA, Shmakov AN, Phillips AD 1995 Human intestinal development in a severe-combined immunodeficient xenograft model. Differentiation 58:361-371

21. Savidge TC 2000 Ectopic transplantation techniques for evaluating gastrointestinal development. In: Sanderson IR, Walker WA (eds) Development of the gastrointestinal tract. B.C. Decker, Hamilton, Ontario, Canada, pp 307-318

22. Department of Health and Social Security 1989 Review of the Guidance on the Research Use of Fetuses and Fetal Material (Polkinghorne Report). CM 762. Her Majesty's Stationary Office, London, pp 1-9

23. Audié JP, Janin A, Porchet N, Copin MC, Gosselin B, Aubert JP 1993 Expression of human mucin genes in respiratory, digestive, and reproductive tracts ascertained by in situ hybridization. J Histochem Cytochem 41:1479-1485

24. Savidge TC, Lowe DC, Walker WA 2001 Developmental regulation of intestinal epithelial hydrolase activity in human fetal jejunal xenografts maintained in severecombined immunodeficient mice. Pediatr Res 50:196-202 
25. Dignass A, Lynch-Devaney K, Kindon H, Thim L, Podolsky DK 1994 Trefoil peptides promote epithelial migration through a transforming growth factor betaindependent pathway. J Clin Invest 94:376-383

26. Chadee K, Petri Jr WA, Innes DJ, Ravdin JI 1987 Rat and human colonic mucins bind to and inhibit adherence lectin of Entamoeba histolytica. J Clin Invest 80:1245-1254

27. Drumm B, Roberton AM, Sherman PM 1988 Inhibition of attachment of Escherichia coli RDEC-1 to intestinal microvillus membranes by rabbit ileal mucus and mucin in vitro. Infect Immun 56:2437-2442

28. Mantle M, Husar SD 1993 Adhesion of Yersinia enterocolitica to purified rabbit and human intestinal mucin. Infect Immun 61:2340-2346

29. Yolken RH, Ojeh C, Khatri IA, Sajjan U, Forstner JF 1994 Intestinal mucins inhibit rotavirus replication in an oligosaccharide-dependent manner. J Infect Dis 169:1002-1006

30. Mack DR, Blain-Nelson PL 1995 Disparate in vitro inhibition of adhesion of enteropathogenic Escherichia coli $\mathrm{RDEC}-1$ by mucins isolated from various regions of the intestinal tract. Pediatr Res 37:75-80

31. Rajkumar R, Devaraj H, Niranjali S 1998 Binding of Shigella to rat and human intestinal mucin. Mol Cell Biochem 178:261-268

32. Mantle M, Basaraba L, Peacock SC, Gall DG 1989 Binding of Yersinia enterocolitica to rabbit intestinal brush border membranes, mucus, and mucin. Infect Immun 57:3292-3299

33. Lowe DC, Savidge TC, Pickard D, Eckmann L, Kagnoff MF, Dougan G, Chatfield SN 1999 Characterisation of candidate live oral Salmonella typhi vaccine strains harbouring defined mutations in aroA, aroC and $h t r A$. Infect Immun 67:700-707

34. Savidge TC, Shmakov AN, Walker-Smith JA, Phillips AD 1997 Intestinal proliferation and infection in childhood. In: Halter F, Winton D, Wright NA (eds) The Gut as a Mode in Cell and Molecular Biology. Kluwer Academic Publishers, London, pp 110-120

35. Huang GTJ, Eckmann L, Savidge TC, Kagnoff MF 1996 Infection of human intestinal epithelial cells with invasive bacteria upregulates apical intercellular adhesion molecule-1 (ICAM-1) expression and neutrophil adhesion. J Clin Invest 98:572-583

36. Eckmann L, Stenson WF, Savidge TC, Lowe DC, Barrett KE, Fierer J, Smith JR, Kagnoff MF 1997 Role of intestinal epithelial cells in the host secretory response to infection with invasive bacteria: bacterial entry induces epithelial prostaglandin $\mathrm{H}$ synthase-2 expression, and prostaglandin E2 and F2 $\alpha$ production. J Clin Invest 100:296-309

37. Seydel KD, Li E, Swanson PE, Stanley SL 1997 Human intestinal epithelial cells produce proinflammatory cytokines in response to infection in a SCID mouse-human intestinal xenograft model of amebiasis. Infect Immun 65:1631-1639

38. Seydel KD, Li E, Zhang Z, Stanley SL 1998 Epithelial cell-initiated inflammation plays a crucial role in early tissue damage in amebic infection of human intestine. Gastroenterology 115:1446-1453

39. Laurent F, Eckmann L, Savidge TC, Morgan GM, Theodos C, Naciri M, Kagnoff MF 1997 Cryptosporidium parvum infection of human intestinal epithelial cells induces the polarised secretion of C-X-C chemokines. Infect Immun 65:5067-5073

40. Sedel KB, Zhang T, Champion GA, Fichtenbaum C, Swanson PE, Tzipori S, Griffiths JK, Stanley SL 1998 Cryptosporidium parvum infection of human intestinal xenografts in SCID mice induces production of human tumor necrosis factor alpha and interleukin-8. Infect Immun 66:2379-2382

41. Lozniewski A, Muhale F, Hatier R, Marais A, Conroy MC, Edert D, le Faou A, Weber M, Duprez A 1999 Human embryonic gastric xenografts in nude mice: a new model of Helicobacter pylori infection. Infect Immun 67:1798-1805

42. Mack DR, Michail S, Wei S, McDougall L, Hollingsworth MA 1999 Probiotics inhibit enteropathogenic $E$. coli adherence in vitro by inducing intestinal mucin gene expression. Am J Physiol 276:G941-G950 